\title{
Proposal of Lightning Risk Assessment Method Based on the Lightning Current Probability Function for Railway Power Supply System
}

\author{
Hitoshi Hayashiya ${ }^{*}$, Masami Hino, Toru Murakami, Yoshihisa Nishimura, Masahiro Miwa, \\ Eiji Yoshino and Masayuki Matsumoto
}

East Japan Railway Company, Japan

\begin{abstract}
A novel assessment method of breakdown probability at suspension insulators supposing the railway DC power supply system are proposed in this paper. This method is based on the well known lightning current probability function and comparison of lightning endurance of traction wire system between conventional DC railway and Shinkansen is performed. It proves that the introduction of grounding wire in DC railway power system is able to avoid only $36 \%$ of flashover at supporting point. The experimental data to confirm the influence of long tail lightning current on tensioned wire and insulators are also shown.
\end{abstract}

Keywords: Railway, traction substation, catenary system, inverse flashover.

\section{INTRODUCTION}

In 1954, the first grounding wire for DC railway power system was installed along Joetsu Line around Numata Substation for $2,260 \mathrm{~m}$. Since then, as a lightning protection for DC railway power system in Japan, surge arresters are normally installed and grounding wire is installed in the heavy lightning region. For instance, in East Japan Railway Company, it is installed in the region where IKL (Isokeraunic Level) is more than 30 days. On the other hand, for the DC $1.5 \mathrm{kV}$ railway power supply system, it has been recognized that the effect of the grounding wire is weaker than that for general power transmission and delivery system.

In this paper, the effect of grounding wire for railway power system is quantitatively estimated based on the lightning current appearance probability function. Using the proposed method, the comparison of the effect of grounding wire between $\mathrm{DC} 1.5 \mathrm{kV}$ railway power system and $\mathrm{AC} 30 \mathrm{kV}$ railway power system is performed.

After that, the influence of the lightning with newly proposed long tail current is experimentally confirmed to avoid the secondary risk by introducing grounding wire system.

\section{SEVEAR LIGHTNIN IN JAPAN IN 2008}

\subsection{Statistical Data}

In summer of 2008, the number of lightning around Tokyo metropolitan area is comparatively large. The number of lightning in August in 2007, 2008 and 2009 in Tokyo metropolitan area whose area is about $8000 \mathrm{~km}^{2}$, and which data is supplied by a private weather forecast company is shown in Fig. (1). As a more official data, Fig. (2) shows the

*Address correspondence to this author at the East Japan Railway Company, Japan; Tel: +81-3-5334-1245; Fax: +81-3-5334-1246;

E-mail: hayashiya@jreast.co.jp history of number of days with lightning in Tokyo, Yokohama and Chiba since 1967 [1].

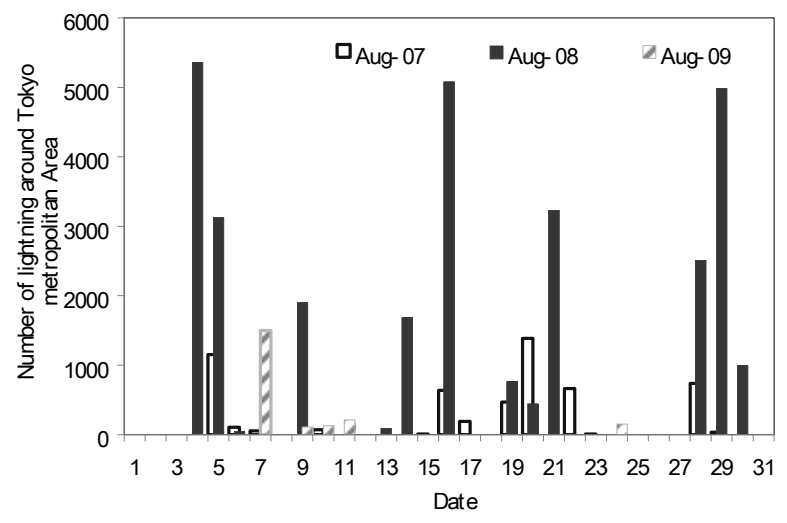

Fig. (1). Comparison of lightning number in August from 2007 to 2009 around Tokyo metropolitan area.

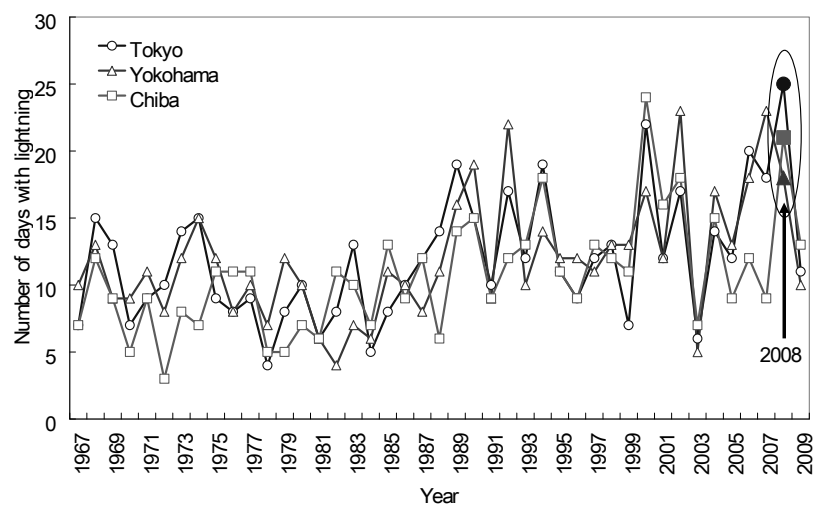

Fig. (2). History of umber of days with lightning in Tokyo, Yokohama and Chiba.

As shown in Fig. (1), the number of lightning in August 2008 is much larger than the other years. The amount of 
lightning number in August 2008 was about 30,000 while those in 2007 and 2009 were about 5,500 and 2,000, respectively.

On August 4th in 2008, the severe thunderstorm hit the western pert of Tokyo that caused the confusion of public service including halts of railway transportation service and large area blackout in electricity service.

The reasons railway transportation halts on August 4th in 2008 were the breaking of a wire in DC $1.5 \mathrm{kV}$ power supply system and troubles in electric signaling system. In this paper, our discussion to evaluate the effect of grounding wire for $1.5 \mathrm{kV}$ railway power system will be mentioned. A novel evaluation method based on the lightning current probability function evaluated its effect to avoid flashover at supporting point of wires in railway power supply system numerically.

\subsection{Procedure of Wire Breaking in Railway Power Supply System}

\subsubsection{Difficulty to Detect Grounding Fault}

In the $1.5 \mathrm{DC}$ electric railway, the electric power more than several MW is supplied by $1.5 \mathrm{kV}$ power supply system and in Tokyo metropolitan area, the supplied current from railway substation for one feeding circuit becomes up to $10 \mathrm{kA}$. Thus, in some cases, the grounding fault current is smaller than the load current and it is difficult to distinguish it from normal load current. Such a difficulty for fault protection in the DC railway power system is one of the reasons of the wire breaking caused by the lighting and it is an important and particular factor to discuss the lightning protection measures for DC railway power supply system.

\subsubsection{Wire Breaking Procedure}

As shown in Section 2.2.1, the ground fault along the railroad is difficult to be detected and once the ground fault happens, it continues in some cases and results in wire breaking at the ground fault point.

Figs. $(3,4)$ shows the typical procedure of wire breaking by lightning, one is a flashover case and another is a back flashover case. The explanations of each procedure are as follows:

\section{(Flashover case)}

1. Lightning strikes overhead contact wire system which is about 5 or $6 \mathrm{~m}$ above railroad track.

2. The surge voltage progresses on the wire circuit in each direction.

3. Flashover happens at the supporting point with two suspension insulators with $180 \mathrm{~mm}$ diameter whose rated breakdown voltage is $150 \mathrm{kV}$.

4. DC current continues and the wire is broken by the arc of grounding fault in several seconds.

(Back flashover case)

1. Lightning strikes supporting structure whose grounding resistance is regulated to be less than 100 ohm.
2. The potential of the structure rises because of the lightning current transiently.

3. Back flashover happens at the supporting point with two suspension insulators with $180 \mathrm{~mm}$ diameter whose rated breakdown voltage is $150 \mathrm{kV}$.

4. DC current continues and the wire is broken by the arc of grounding fault in several seconds.

In each case, if the surge arrester is located near the supporting point, it will avoid flashover and back flashover in some cases. Here, surge arresters are facilitated along the contact wire system with an interval of $500 \mathrm{~m}$ in Tokyo metropolitan area.

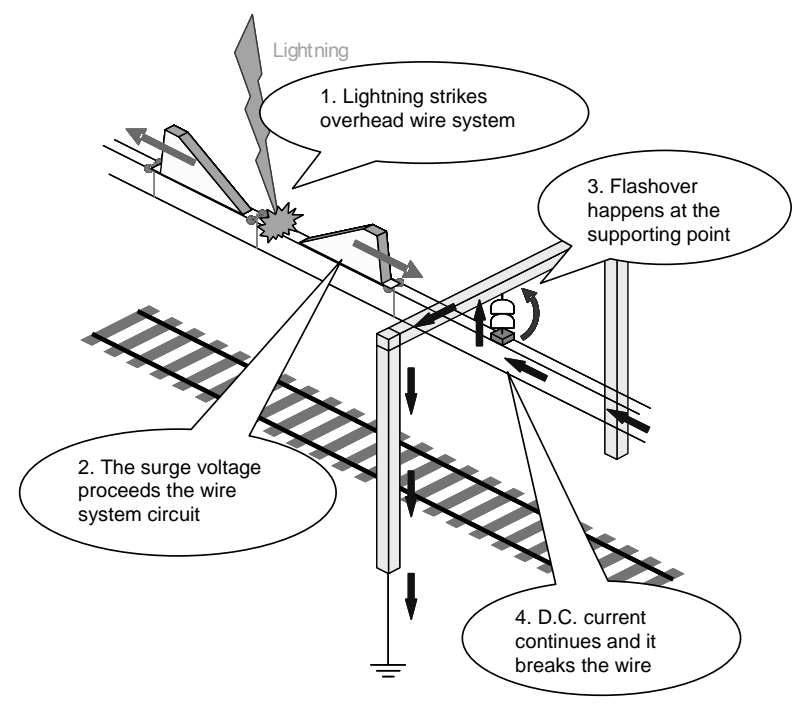

Fig. (3). Wire breaking procedure by lightning (flashover case).

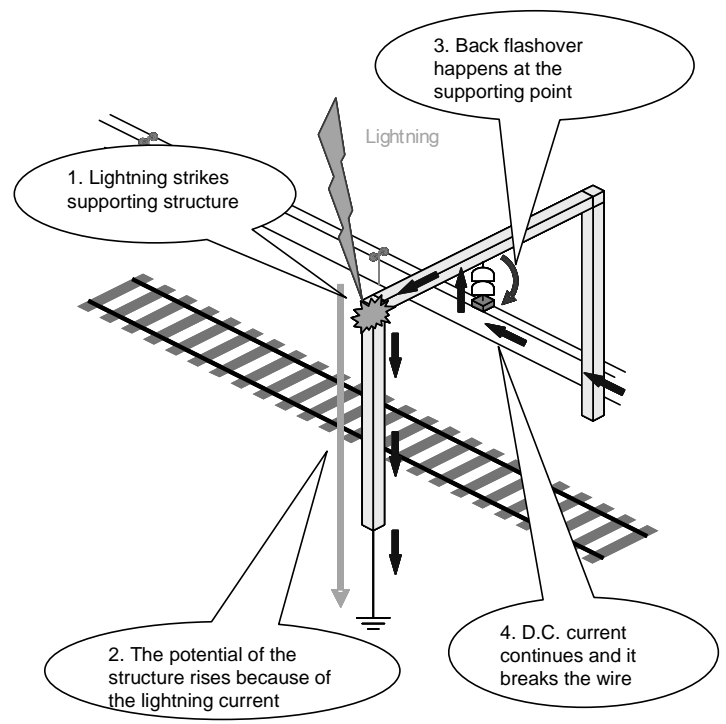

Fig. (4). Wire breaking procedure by lightning (back flashover case). 


\subsubsection{Concept of Grounding Wire for Railway Power System in Japan}

The excerpts of the concept of grounding wire facility for lightning protection in former Japan National Railway (JNR) are summarized as follow:

- It is facilitated at railway substation and in the heavy lightning region.

- $\quad$ It is composed of zinc-coated steel strand with $55 \mathrm{~mm}^{2}$ cross sectional area.

- Its protection angle is considered to be 45 degree.

- It is grounded every $200 \mathrm{~m}$ with $30 \mathrm{ohm}$ grounding resistance.

- In DC railway, it is electrically divided with an interval of $200 \mathrm{~m}$ and grounded near the center of each grounding wire.

- If necessary, it is supported by suspension insulator whose diameter is $180 \mathrm{~mm}$ and insulated from supporting structure. Japan.

They are almost succeeded by the railway companies in

\section{EVALUATION OF GROUNDIGN WIRE FOR LIGHTNING PROTECTION}

\subsection{Lightning current probability function}

To evaluate the effect of grounding wire for lightning protection of railway power supply system, the current value of lightning is necessary.

In reference [2], statistics of measured lightning current in Japan is summarized and it is shown in Table $\mathbf{1}$ and Fig. (5). In Fig. (5), famous empirical formula given by J. G. Anderson as shown in Equation (1) is also plotted $[3,4]$.

$P(I)=\frac{1}{1+(I / 31)^{2.6}}$

According to Table 1, the average value of lightning current is from $15 \mathrm{kA}$ to $50 \mathrm{kA}$. For our evaluation, as a moderate index, empirical formula in Equation (1) whose average value is $31 \mathrm{kA}$ is used as a lightning current probability function in the following discussion.

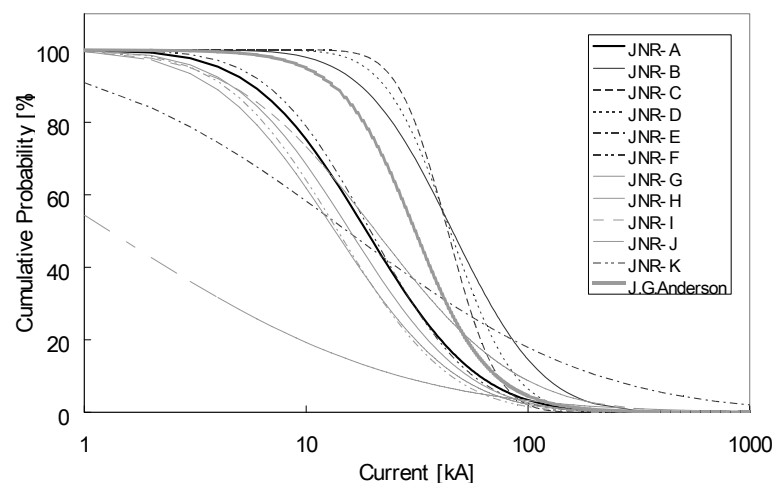

Fig. (5). Cumulative appearance probability of lightning current.

\subsection{Validity of Used Probability Function}

To confirm the validity of Equation (1), the lightning current data given by private weather forecast company on August 5th 2007, August 4th 2008 and August 5th 2008 are statistically handled and compared with Equation (1) in Fig. (6).

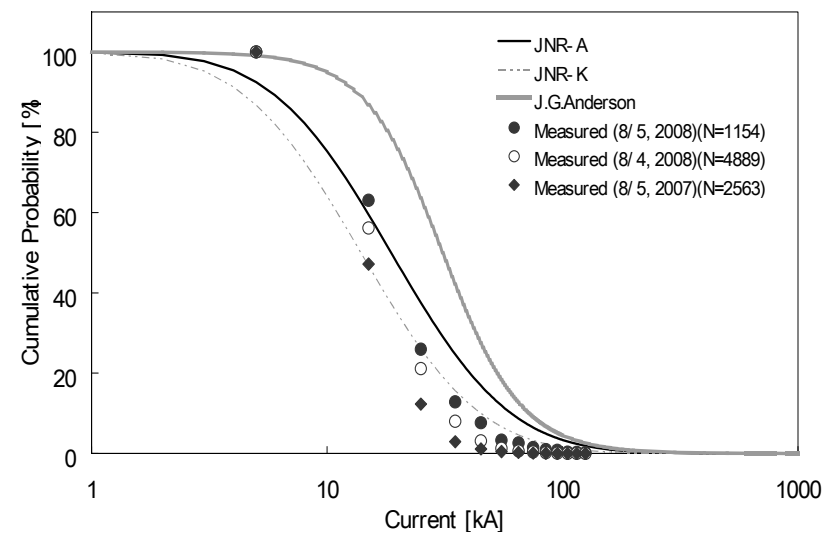

Fig. (6). Comparison between empirical formula and measured data.

Table 1. Measured Lightning Current in Japan 40 Years Ago

\begin{tabular}{|c|c|c|c|c|c|c|}
\hline \# & Target & Device *1 & Number of Data & Average $\left(\log _{10}\right)$ & Standard Dev. $\left(\log _{10}\right)$ & Max. \\
\hline A & General ground & OSC & 96 & $18.7 \mathrm{kA}$ & $2.5 \mathrm{kA}$ & $155 \mathrm{kA}$ \\
\hline $\mathrm{C}$ & Transmission line $(77,145 \mathrm{kV})$ & ML & 27 & $43.5 \mathrm{kA}$ & $1.5 \mathrm{kA}$ & $81 \mathrm{kA}$ \\
\hline $\mathrm{D}$ & Transmission line $(66,154 \mathrm{kV})$ & ML & 84 & $44.6 \mathrm{kA}$ & $1.7 \mathrm{kA}$ & $131 \mathrm{kA}$ \\
\hline $\mathrm{F}$ & Transmission line & ML & 983 & $19.5 \mathrm{kA}$ & $2.3 \mathrm{kA}$ & $400 \mathrm{kA}$ \\
\hline G & Building $(20-150 \mathrm{~m})$ & OSC, ML & 46 & $15.8 \mathrm{kA}$ & $2.6 \mathrm{kA}$ & $160 \mathrm{kA}$ \\
\hline $\mathrm{H}$ & Transmission line $(60,220 \mathrm{kV})$ & ML & 2721 & $13.5 \mathrm{kA}$ & $2.7 \mathrm{kA}$ & $218 \mathrm{kA}$ \\
\hline I & Transmission line $(15 \mathrm{kV})$ and others & ML & 126 & $20.6 \mathrm{kA}$ & $3.2 \mathrm{kA}$ & $515 \mathrm{kA}$ \\
\hline
\end{tabular}

*1 OSC: oscillograph, ML: magnetic link. 
In the data handling, the current data with same measured time is abandoned to be considered as a multiple stroke flashes and only the maximum current value among them are used for probability calculation. For a comparison, the cumulative curve of $\mathrm{A}$ and $\mathrm{K}$ in Table $\mathbf{1}$ and Fig. (5) is also shown in Fig. (6).

The average value of measured current is estimated roughly around $20 \mathrm{kA}$. Thus, the evaluation based on Equation (1) is supposing a little bit severe lightning.

\subsection{Precondition for Evaluation}

For the evaluation of the effect of grounding wire for lightning protection, it is enough to consider only a back flashover procedure for wire breaking risk assessment.

The preconditions for evaluation are as follows [5, 7]:

- The insulation levels of one suspension insulator are $75 \mathrm{kV}$ for $180 \mathrm{~mm}$ insulator and $105 \mathrm{kV}$ for $250 \mathrm{~mm}$ insulator.

- The lightning on grounding wire is divided into two equal surge current in each direction.

- $\quad$ The surge current arrives at supporting structure is again divided into two equal current.

- $\quad$ Thus, one fourth of the lightning current contributes the transient potential rise of the supporting structure.

- In the case without grounding wire, the whole lightning current contributes to the structural potential rise.

- The static combination of electrically pressurized wires which is facilitated with grounding wire in parallel is taken into account as a combination coefficient 0.2 .

- In other words, the voltage difference appeared at the both side of the insulator is 0.8 of the structural potential rise.

- The grounding resistance is $30 \mathrm{ohm}$.

\subsection{Evaluation of Relation Between Insulation Level and the Effect of Grounding Wire}

For the evaluation of the effect of grounding wire for lightning protection, it is enough to consider only a back flashover procedure for wire breaking risk assessment.

In Fig. (7), relation between the number of the suspension insulators and the flashover probability are shown. Here, the flashover probability means how often the flashover at the supporting point happens when a lightning strikes a grounding wire of railway power supply system. After calculating the potential rise at supporting point caused by lightning transient current, the probability of backflashover is derived using Equation (1). Thus, "flashover probability" means how often the back-flashover happens when a lightning hits the traction power supply system. Here, the frequency how often a lighting hits traction power supply system is not taken into account.

In Table 2, insulation level of suspension insulators in railway power supply system is shown. As shown in Fig. (7), the introduction of grounding wire in $\mathrm{DC} 1.5 \mathrm{kV}$ power supply system is able to reduce the risk of flashover only $64 \%$ while it is $12 \%$ in AC25kV Shinkansen power supply system. As the insulation level is lower in DC conventional railway, the effect of grounding wire is much smaller than that in AC railway power supply system. We have to take these effects into account to discuss the measures against lightning of railway power supply system.

(a) $180 \mathrm{~mm}$ suspension insulator

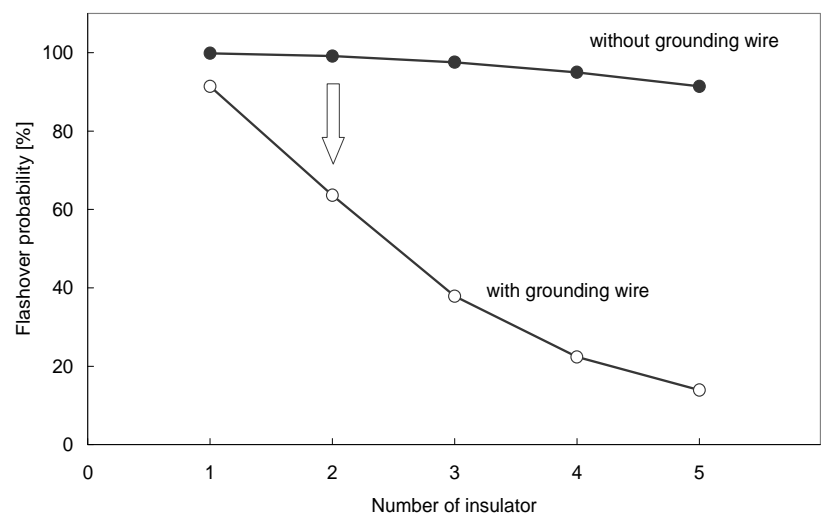

(b) $250 \mathrm{~mm}$ suspension insulator

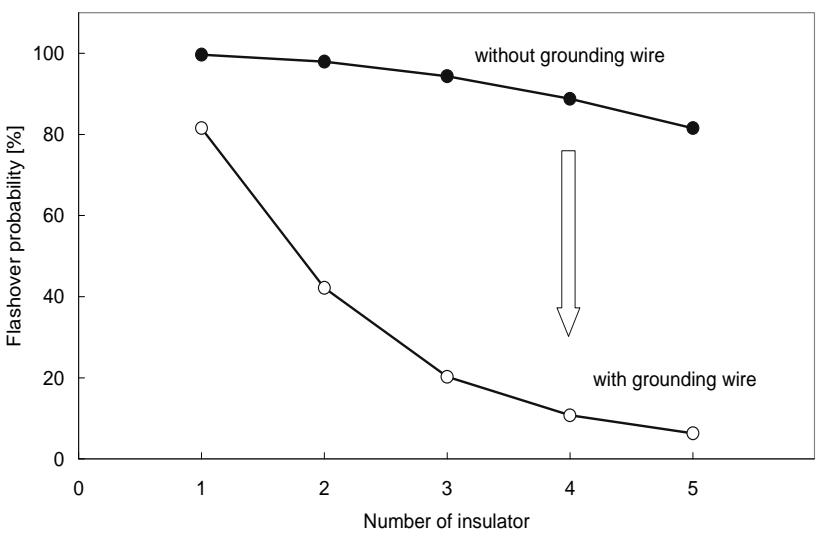

Fig. (7). Relation between number of suspension insulator and flashover probability.

Table 2. Insulation Level of Suspension Insulator

\begin{tabular}{|c|c|c|c|}
\hline & Diameter & $\begin{array}{c}\text { Number of } \\
\text { Insulators }\end{array}$ & $\begin{array}{c}\text { Insulation } \\
\text { Level }\end{array}$ \\
\hline \hline $1.5 \mathrm{kV}$ conventional railway & $180 \mathrm{~mm}$ & 2 & $150 \mathrm{kV}$ \\
\hline $20 \mathrm{kV}$ conventional railway & $250 \mathrm{~mm}$ & $3(4)$ & $315 \mathrm{kV}$ \\
\hline $25 \mathrm{kV}$ Shinkansen & $250 \mathrm{~mm}$ & $4(5)$ & $420 \mathrm{kV}$ \\
\hline
\end{tabular}

( ) : value in heavy pollution area.

In conventional railway in our company, the breaking of wire caused by lightning happens almost every two years while it never happens in Shinkansen power system. The strength of Shinkansen power supply system against lightning is thought to be as follows:

- The supply voltage in Shinkansen power supply system is high enough and it is easy to detect ground fault along the railroad track. 
- $\quad$ Protective wire is equipped in Shinkansen power supply system and most of a ground fault is quickly shifted to a short circuit fault.

- Grounding wire is properly furnished in Shinkansen power supply system.

Judging from the evaluation results shown in Fig. (7), it is necessary to know that its effect of grounding wire is not so remarkable in DC railway power supply system.

\subsection{Evaluation of Flashover Probability at Railway DC Substation}

Fig. (8) shows the evaluation results of flashover probability at DC railway substation based on lightning current probability function. If grounding resistance of substation is more than about $2 \mathrm{ohm}$, a lightning strike on substation always results in back flashover at supporting insulator. It is possible to estimate by proposing method that the risk of back flashover at railway substation will be about $50 \%$ when the grounding resistance is improved to be less than $1 \mathrm{ohm}$.

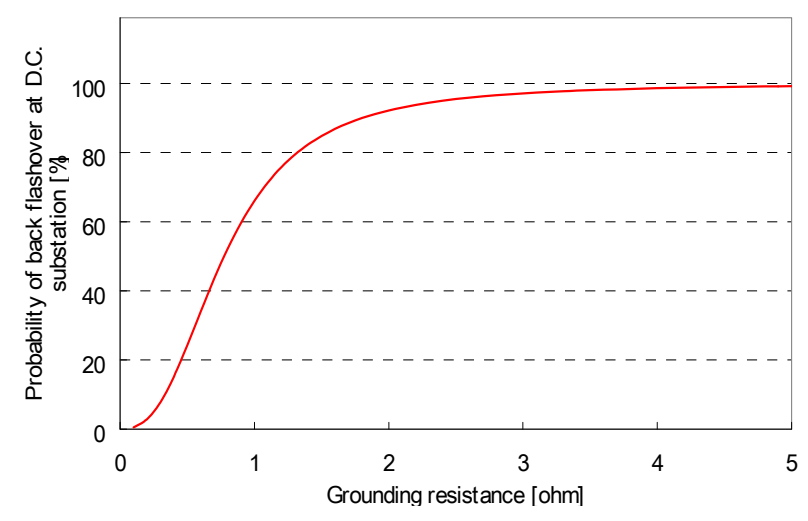

Fig. (8). Back flashover probability at DC railway substation.

\section{EXPERIMENTS}

\subsection{Purpose of the Experiments}

The influence of direct lightning strokes on railway contact wire is also confirmed to avoid secondary troubles by introducing grounding wire or protective wire into DC railway power system $[6,8]$.

Overhead wires above railway track are stretched intentionally by weight or spring tension balancers for smooth running of pantographs under the wire. So, we have to pay attention to the influence of the strong tension on wire breaking characteristics by thunder lightning. Here, the long tail lightning impulse current (10/350 micro second) is used for the tests to evaluate severe conditions. Fig. (9) shows some photographs of the experimental machine. The wire is stretched by weight tension balancer using pulley principle which is able to apply strong tension about 10 or $20 \mathrm{kN}$ on various kinds of wires. The long tail lightning impulse tests were performed at Nissin Electric Co., Ltd. in Kyoto, Japan.

\subsection{Experimental Results}

About the influence on feeder messenger wire, the wire made of hard drawn copper stranded wire was exposed to $25 \mathrm{kA}$ long tail impulse current as shown in Fig. (10) with a
$10 \mathrm{~mm}$ interval. The photograph of the exposed feeder messenger wire is shown in Fig. (11). As shown in this figure, no element wire is broken or shaved by the impulse current. Similar tests were performed on contact wire, messenger wire, feeder wire and grounding wire. Further more, supposing a multiple-stroke flash, the test was repeated on the same wire 10 times and no abrasion is also confirmed.

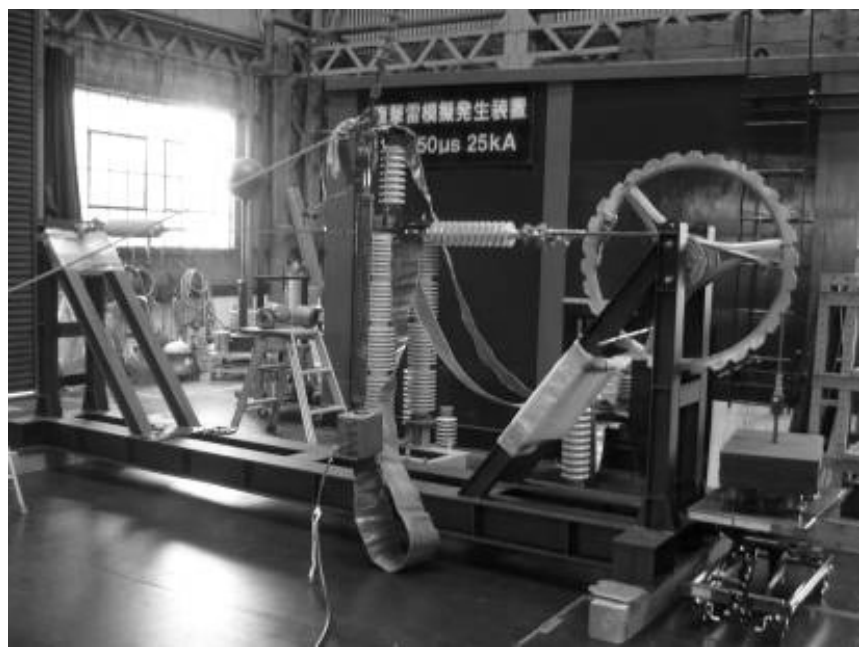

Fig. (9). Photograph of experimental machine.

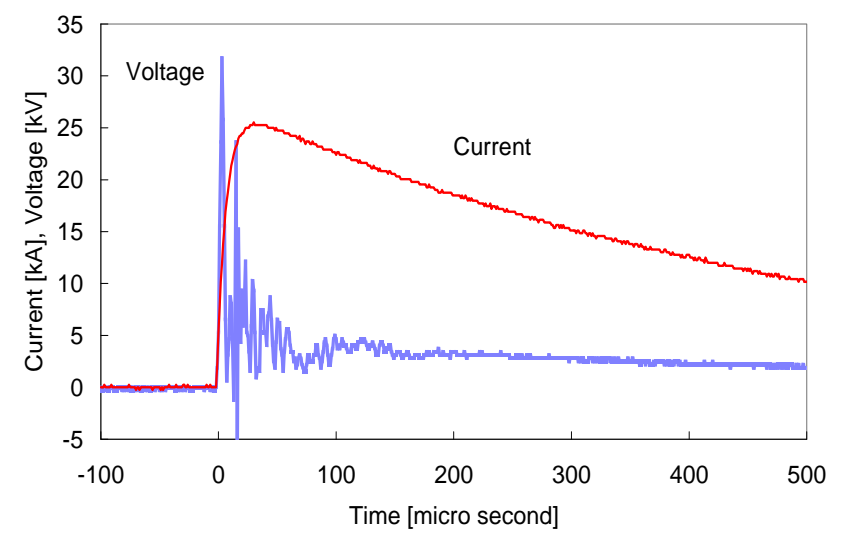

Fig. (10). Impulse voltage and current waveforms.

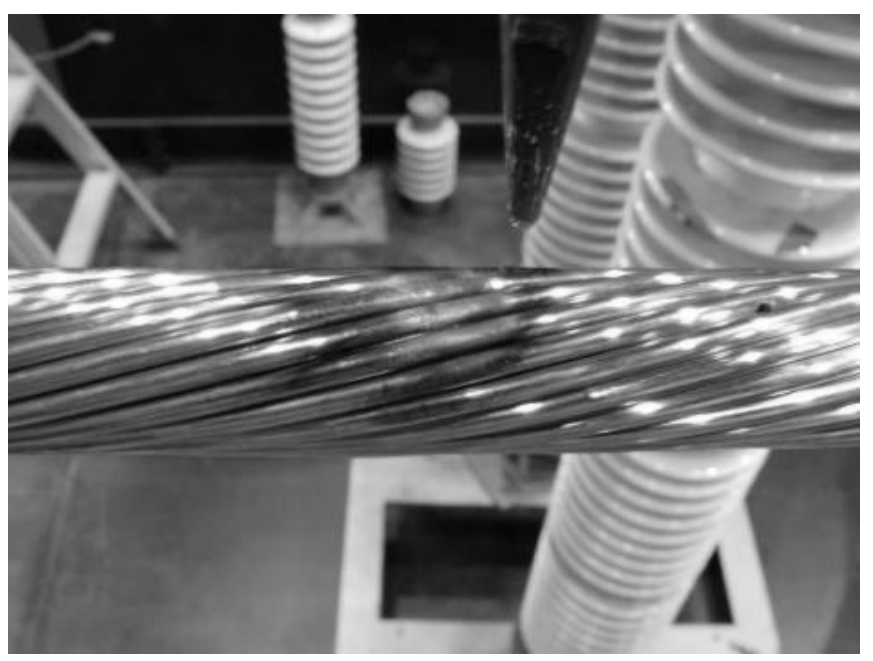

Fig. (11). Influence of long tail lightning current on stranded wire. 
Fig. (12) shows the influence on suspension insulator. As shown in this figure, the surface of the insulator was not broken even by $25 \mathrm{kA}$ long tail current whose energy is twenty times as large as conventional lightning current waveform.

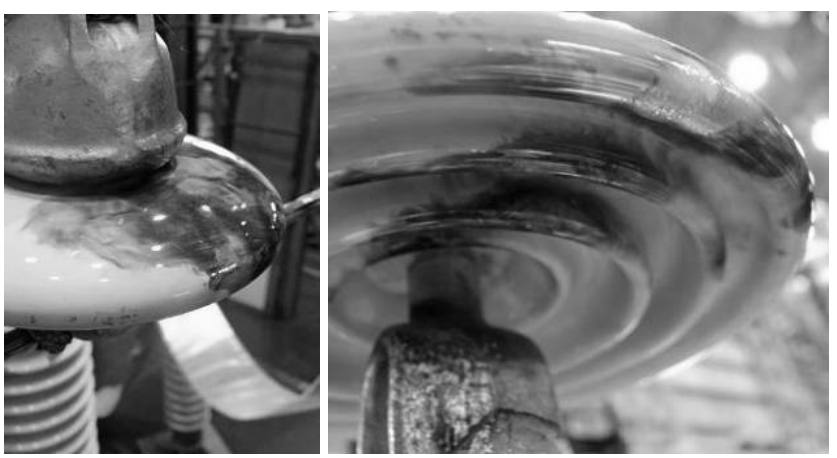

Fig. (12). Influence of long tail lightning current on surface of suspension insulator.

\section{CONCLUSIONS}

A novel simple estimation method based on the lightning current probability function is proposed. Using the proposed method, the effect of the grounding wire in $\mathrm{DC} 1.5 \mathrm{kV}$ railway power system is evaluated. It is important to recognize that the grounding wire of DC railway power system is able to avoid flashover at supporting point of railway catenary system only $36 \%$ while that of $\mathrm{AC}$ Shinkansen system is $88 \%$. Such a difference is well coincides with our experiences. Back-flashover probability at DC railway substation is also evaluated and it is proposed to make resistance of grounding system less than $2 \mathrm{ohm}$ to avoid back-flashover at the supporting point. Lastly but not least, the endurance of the wire used for DC railway power system is experimentally confirmed using long tail impulse current when the wire is intentionally tensed by weight tension balancer. Even by $25 \mathrm{kA}$ long tail waveform, both wires and insulators are not broken. Thus, if the about $50 \%$ reduction effect of introduction of grounding wire for DC railway power system is satisfactory for investment, introduction of grounding wire for DC railway power system will be one of the countermeasures against lightning.

We would like to continue making effort to share our knowledge with other organizations [9, 10] and make traction power supply system more reliable and more safety in the future.

\section{ACKNOWLEDGEMENT}

Through our investigation, we were instructed and supported by Dr S. Yokoyama of central research institute of electric power industry (CRIEPI) cordially. The impulse tests were conducted by special engineers of Nisshin Electric Co., Ltd, Mr. T. Tanaka and Mr. T. Heike. Mr. M. Hino of East Japan Railway Company was also supported the experiments. We acknowledge for all of their supports.

\section{CONFLICT OF INTEREST}

Declared none.

\section{REFERENCES}

[1] Web Page of Japan Meteorological Agency. Available at: http://ww w.data.jma.go.jp/obd/stats/etrn/index.php [Accessed: 2010/5/21].

[2] Japan National Railway. Research of insulation co-ordination for railway electrification. 1971; pp. 35-39 (in Japanese).

[3] Yokoyama S. Lightning protection for distribution power lines. Ohmsha 2005 (in Japanese).

[4] Anderson JG. Lightning performance of transmission lines. In: Chapter 12 of transmission line reference book, $345 \mathrm{kV}$ and above. 2nd ed. Electric Power Research Institute (EPRI) 1981.

[5] Hayashiya $\mathrm{H}$. Evaluation of grounding wire for DC railway power system based on the lightning current appearance probability. The Papers of Technical Meeting, IEEJ, No.TER-10-001, 2010. (in Japanese).

[6] Hayashiya H, Hino M. Influence of long tail lightning impulse current on bare stranded feeder wire", 2010 Annual Conference of IEE of Japan. No.5-054, 2010 (in Japanese).

[7] Hayashiya H, Koguchi N, Kaneko C. Proposal of a effect estimation of the measures against the thunder lightning based on the lighting current appearance probability function. 2009 Annual Conference of IEE of Japan, Industry Application Society, No.R31-8, 2009 (in Japanese).

[8] Hayashiya $\mathrm{H}$, SakurabaY. Influence of the frequent discharge on $\mathrm{ZnO}$ surge arrester characteristics for Shinkansen power system. $28^{\text {th }}$ International Conference on Lightning Protection (ICLP2006) 2006; pp. 1021-6.

[9] Delfino F, Procopio R, Borghetti A, Nucci CA, Paolone M, Rachidi F. Comparison of different approaches for the evaluation of lightning-induced overvoltages in light-rail DC traction power systems. $28^{\text {th }}$ International Conference on Lightning Protection (ICLP2006) 2006; pp. 471-8.

[10] Richter B, Schafer S. Lightning and overvoltage protection concept for urban transportation. $28^{\text {th }}$ International Conference on Lightning Protection (ICLP2006) 2006; pp. 1273-8. 